\title{
Behavior analysis of high strength concrete containing macro- polymeric fibers based on workability and mechanical properties
}

Anallisis del comportamiento dell hormigón de alla resistencia
con macrofilbra polimérica basado en la trabajabilidad y las
propiedades mecánicas

\author{
Alex Macedo ${ }^{1 *}$ https://orcid.org/0000-0003-4022-6787, \\ Alessandra Lorenzetti de Castro * https://orcid.org/0000-0002-7248-7327 \\ * University of São Paulo - São Carlos, BRAZIL
}

Fecha de Recepción: 22/04/2021

Fecha de Aceptación: 14/07/2021

PAG 142-156

\begin{abstract}
The main purpose of fiber reinforcement in concrete is to increase the post-cracking resistance of the composite, which reflects on toughness gain, being steel fibers traditionally used for this purpose. In recent years, an alternative to the steel fibers has emerged in the market for concrete reinforcement: the macro-polymeric fiber. However, there is few research on its performance as a reinforcement element in concrete, particularly when it is a high strength concrete. Given this, the behavior of high strength concrete, without fiber and with macro-polymeric fiber, both in fresh and hardened state, is analyzed in this paper. The workability was evaluated by the slump test and the mechanical properties were evaluated by the tests of compressive strength, Barcelona, flexure of prisms and punching of plates. It was found that, depending on the property to be analyzed, the increase of the macro-polymeric fiber content may be unfeasible. In the flexural test in prisms, for example, most parameters evaluated showed no significant changes when increasing the fiber content. In addition, it was observed that the same concrete mixture may present different behavior depending on the test performed.
\end{abstract}

Keywords: Fiber reinforced concrete, macro-polymeric fiber, workability; toughness

Resumen

El objetivo principal del refuerzo con fibras en el hormigón es aumentar la resistencia post-fisuración del compuesto, lo que se refleja en una ganancia de tenacidad, siendo las fibras de acero las que tradicionalmente se utilizan para este fin. En los últimos años, ha surgido en el mercado una alternativa a las fibras de acero para el refuerzo del hormigón: la fibra macro-polimérica. Sin embargo, existen poca investigacón sobre su comportamiento como elemento de refuerzo en el hormigón, especialmente cuando se trata de un hormigón de alta resistencia. Ante esto, este trabajo analiza el comportamiento del hormigón de alta resistencia, sin fibra y con fibra macropolimérica, tanto en estado fresco como endurecido. La trabajabilidad se evaluó mediante el ensayo de asentamiento, y las propiedades mecánicas se evaluaron mediante los ensayos de resistencia a la compresión, Barcelona, flexión de prismas y punzonamiento de placas. Se comprobó que, dependiendo de la propiedad a analizar, el aumento del contenido de fibra macro-polimérica puede ser inviable. En el ensayo de flexión en prismas, por ejemplo, la mayoría de los parámetros evaluados no mostraron cambios significativos al aumentar el contenido de fibra. Además, se observó que una misma mezcla de hormigón puede presentar un comportamiento diferente en función del ensayo realizado.

Palabras clave: Horrmigón reforzado con fibra, fibra macro-polimérica, trabajabilidad; tenacidad

\section{Introduction}

Considered a composite material, concrete consists of a cementitious matrix reinforced with aggregates. Some types of concrete, such as high strength concrete and fiber reinforced concrete, have unique properties and are called special concrete. High strength concrete is characterized by a higher compressive strength than the ordinary concrete, while fiber reinforced concrete has post-cracking residual resistance of the cementitious matrix. When added to the concrete, fibers act as a stress transfer bridge along the cracks, hindering their propagation and minimizing the occurrence of the stress concentration at the crack tip. Consequently, concrete is no longer a fragile material and becomes a pseudo-ductile material, showing post-cracking resistance (Figueiredo, 2011). The properties of the cementitious matrix, besides the type and content of fiber added are the main aspects that will define the post-cracking behavior of fiber reinforced concrete.

The properties that most influence the performance of the fibers in concrete are their mechanical strength and modulus of elasticity. Low modulus fibers, such as polypropylene fibers, reach relatively low stresses at the moment of matrix failure, and a high content of these fibers is required to withstand the stress transferred by the matrix. On the other hand, high modulus fibers, such as steel fibers, have a high level of stress when the composite reaches its critical deformation before failure, allowing a high level of reinforcement when the matrix fails, with a lower fiber content if its strength is not exceeded (Figueiredo, 2011).

\footnotetext{
${ }^{1}$ Corresponding author:

University of São Paulo - São Carlos, BRAZIL

E-mail: alexmacedoleite@gmail.com
} 
Traditionally, steel fibers have been used for primary reinforcement of the concrete, i.e., the increase in the post-cracking resistance of the composite, which reflects on toughness gain. However, more recently, macropolymeric fibers began to be commercialized in order to provide post-cracking resistance to the concrete (The Concrete Society, 2007; Amin et al., 2017). Macro-polymeric fibers, due to their lower modulus of elasticity as well as their crimped shape, show higher deformation at peak load, toughness, post-cracking load-carrying capacity and reduced crack width (Fallah and Nematzadeh, 2017). Among the several factors that justify the use of these fibers in concrete, it is noteworthy that they are made of polypropylene, a chemically inert material, are resistant to corrosion, do not absorb water, have low cost and weight, and are easily available (Medeiros, 2012). In high strength concrete, whose cementitious matrix is denser, there is a better adherence between the two phases (matrix and fibers), which reflects in the post-cracking behavior (Figueiredo, 2000). However, there is few research on their performance as a reinforcement element in concrete, particularly when it is a high strength concrete.

The post-cracking behavior of concrete reinforced with steel fibers and macro-polymeric fibers was evaluated by (Buratti, Mazzotti and Savoia, 2011), considering different types of macro-polymeric and steel fibers, added in a moderate compressive strength cementitious matrix. From flexural tests in prisms, it was verified a better performance of steel fibers when compared to the synthetic fibers, considering a similar number of fibers in the crack propagation region. However, there was a greater variation of the results in the samples with steel fibers than in those with macro-polymeric fibers, considering similar contents of fiber added. According to the authors, this was due to the higher number and greater homogeneity of the macro-polymeric fibers in relation to the steel fibers in the cracked section. The post-cracking behavior of macro-polymeric fiber reinforced concrete, with characteristic compressive strength of $50 \mathrm{MPa}$, was also investigated by (Amin et al., 2017) through the uniaxial tension tests, that measure tension directly, and the prism bending and round panel tests, that measure tension indirectly. They observed that after cracking a significant drop in strength occurred for all concrete studied and over increasing the vertical displacement the capacity of the specimens increased, showing a slip-hardening behavior. In the round panel tests, three dominant radial cracks formed in all specimens, which coincided with a reduction in the load panels capacity. However, after the cracking, a drop in the initial load was verified well below that of the peak residual strength of the macro-polymeric fiber reinforced concrete, showing a progressively smooth residual capacity lost of the specimens. With the purpose of evaluating the flexural capacity of macro-polymeric fiber reinforced concrete, (Lee et al., 2016) produced an experimental study considering different fiber volume fractions and concrete compressive strength (30, 40, and $60 \mathrm{MPa}$ ). The addition of low macro-polymeric fiber contents in high strength concrete resulted in a flexural capacity lower than ordinary strength concrete reinforced with similar macro-polymeric fiber content. According to the authors, there was a significant variation in the flexural capacity of high strength concrete when using macro-polymeric fiber contents of more than $0.50 \%$, by volume. In the study developed by (Fallah and Nematzadeh, 2017), the effect of adding macro-polymeric and polypropylene fibers on the durability and mechanical properties of high strength concrete containing nanosilica and silica fume was evaluated. The extensive experimental study results suggest an improvement in the concrete behavior with the incorporation of mineral additions, as well as the addition of macro-polymeric fiber in a given content improves the mechanical properties of the high strength concrete. In contrast, the addition of high polypropylene fiber contents impaired the physical-mechanical behavior of the concrete. In Brazil, (Salvador and Figueiredo, 2013) analyzed the mechanical properties of a $35 \mathrm{MPa}$-mean compressive strength concrete reinforced with macro-polymeric and steel fibers, being considered different contents of both types of fibers. From the results obtained in flexural tests in prisms, correlations were established between fiber content and toughness evaluation parameters and between macro-polymeric fiber and steel fiber contents, considering certain performance criteria. It was found that macropolymeric fiber can be used to replace steel fiber as long as performance-equivalent fiber contents are considered. Leite and Castro (2020) analyzed the cementitious matrix influence on fiber reinforced concrete behavior, considering mixtures with mean compressive strength of $40 \mathrm{MPa}$ and $70 \mathrm{MPa}$, produced with steel and macropolymeric fibers. According to the results of the mechanical tests performed in the study, there was no change in the performance pattern of the mixtures reinforced with macro-polymeric fibers when changing the cementitious matrix. The authors observed a significant variation in the toughness of the macro-polymeric fiber reinforced concrete evaluated by Barcelona and bending tests when cementitious matrix was changed, while in the punching test the change was not significant. Considering the same fiber content, they observed a performance equivalence between the steel and macro-polymeric fibers in terms of toughness when changing the concrete cementitious matrix.

Thus, in the context of the use of macro-polymeric fibers as the primary reinforcement element of Portland cement concrete mixtures, since the data available on the performance of these reinforced fiber concrete are limited, particularly when considering high compressive strength, the present study aims to evaluate the behavior of high strength concrete reinforced with macro-polymeric fiber, added in the contents of $1 \%$ and $2 \%$, by volume. For 
this, the workability of the concrete mixtures produced was evaluated, and their mechanical properties was measured by the tests of compressive strength, Barcelona, flexure of prisms and punching of plates.

\section{Experimental Program}

\subsection{Materials}

Concrete mixtures were produced using a pozzolan-modified Portland cement, with specific gravity of 3.05 $\mathrm{kg} / \mathrm{dm}^{3}$ and compressive strength class of $32 \mathrm{MPa}$, as well as a non-densified silica fume with specific gravity of $2.21 \mathrm{~kg} / \mathrm{dm}^{3}$. Two natural quartzous sands, classified as fine and medium sand, were used as fine aggregate, with specific gravity of 2.58 and $2.57 \mathrm{~kg} / \mathrm{dm}^{3}$, fineness modulus of 1.2 and 2.4, and maximum characterized particle size of 0.6 and $2.36 \mathrm{~mm}$, respectively. Fine aggregate was composed of $60 \%$ of medium sand and $40 \%$ of fine sand, determined by the compacted unit weight test (ABNT, 2006). A basaltic crushed stone was used as coarse aggregate, with specific gravity of $2.96 \mathrm{~kg} / \mathrm{dm}^{3}$ and maximum characteristic particle size of $19 \mathrm{~mm}$.

Water from the local water supply was used. The consistency for the mixtures was reached by adjusting the polycarboxylate based superplasticizer admixture content, since the water/cement ratio was kept constant. The slump value, measured as stated by the Brazilian standard NBR NM 67:1998 (ABNT, 1998), was set at (120 \pm 20 ) $\mathrm{mm}$.

For the mixtures with fibers, it was used a polypropylene macrofiber, with a rectangular cross-section, straight shape and with grooves on the surface, so that anchorage occurred along their length. The physical and mechanical properties of the macro-polymeric fiber used, according to the manufacturer, are: aspect ratio of 75; length of 50 $\mathrm{mm}$; specific gravity of $0.95 \mathrm{~g} / \mathrm{cm}^{3}$; tensile strength of $550 \mathrm{MPa}$; and modulus of elasticity of $7 \mathrm{GPa}$.

\subsection{Mix design and production of the high strength concrete}

A reference high strength concrete (CARR), without fiber, was initially produced, with a mean compressive strength of $70 \mathrm{MPa}$ at the age of 28 days, whose mix design, by mass, was $1: 1,70: 1,80: 0,35$, with silica fume incorporated in the content of $10 \%$ in substitution to cement (by volume). (Table 1) presents the materials consumption for this mix design. Then two new high strength concrete mixtures with macro-polymeric fiber were produced, being the macrofiber added at the content of 1.0\% (CAR1OPP) and 2.0\% (CAR2OPP), by volume, which is equivalent to the macrofiber consumptions of 9.5 and $19 \mathrm{~kg} / \mathrm{m}^{3}$, respectively.

Table 1. Consumption of materials for CARR (without fibers)

\begin{tabular}{|c|c|}
\hline Material & Consumption of materials $\mathbf{( k g / \mathbf { m } ^ { 3 } )}$ \\
\hline Cement & 468 \\
\hline Silica fume & 39 \\
\hline Crushed stone & 936 \\
\hline Medium sand & 531 \\
\hline Fine sand & 354 \\
\hline Water & 164 \\
\hline Superplasticizer & 3.0 \\
\hline
\end{tabular}

In the production of concrete mixtures, dry materials were used, following the same order of materials incorporation in the mixer. First, fine and coarse aggregates were mixed with part of the water for 1 minute. Then cement, silica fume and the remaining water were added and mixed for 5 minutes. The superplasticizer admixture was then incorporated into the mixture, which continued for a further 5 minutes. For the concrete with fibers, macro-polymeric fiber was added at the end of the mix. The admixture content was adjusted during the concrete mixing procedure, making successive additions until the mixtures were within the established slump value range. 
After the concrete production, specimens were molded, being mechanically compacted on a vibrating table, and protected with a plastic film at the top to avoid the moisture loss from the concrete. After 24 hours the specimens were demolded and subjected to a continuous moist cure until the age of 28 days, when the mechanical tests were performed.

\subsection{Evaluation of the concrete properties in the hardened state}

The compressive strength of the high strength concrete, without and with macro-polymeric fiber, was determined according to the specifications of the Brazilian standard NBR 5739:2018 (ABNT, 2018). To evaluate the tensile strength, residual strength and toughness of all concrete mixtures produced it was performed three mechanical tests: Barcelona (double punching test), flexural in prisms and punching in plates. Barcelona test was performed as stated by the Spanish standard UNE 83515:2010 (AENOR, 2010), with a machine piston displacement speed equal to $0.5 \mathrm{~mm} / \mathrm{min}$. The procedure established by the Japanese standard JSCE-SF4 (JSCE, 1984) was employed for the flexural test in prisms, considering a machine piston displacement speed of $0.15 \mathrm{~mm} / \mathrm{min}$. The European recommendation EFNARC (1996) was used for the punching test in plates, considering a machine piston displacement speed of $1.5 \mathrm{~mm} / \mathrm{min}$.

All mechanical tests were performed at the age of 28 days. For each test, the average (mean value) of the individual results obtained in the specimens and the coefficient of variation were considered. (Table 2) presents the type, quantity and dimensions of the specimens used in the tests, for each concrete mixture produced. In addition, to verify the influence of the macro-polymeric fiber on the mechanical behavior of high strength concrete, and also to analyze the relevance of adding different macrofiber contents to the concrete properties, a statistical analysis of the results was performed, applying Student's t-test, with a 95\% confidence level.

Table 2. Details of the specimens tested in each test performed in the study

\begin{tabular}{|c|c|c|c|}
\hline \multirow{2}{*}{ Test } & \multicolumn{3}{|c|}{ Specimens } \\
\cline { 2 - 4 } & Type & Quantity & Dimensions (mm) \\
\hline Compressive strength & Cylindrical & 5 & $100 \times 200$ \\
\hline Barcelona & Cylindrical & 3 & $150 \times 150$ \\
\hline Flexural in prisms & Prismatic & 3 & $150 \times 150 \times 500$ \\
\hline Punching in plates & Plate & 3 & $100 \times 600 \times 600$ \\
\hline
\end{tabular}

\section{Results and Discussions}

\subsection{Concrete properties in the fresh state}

(Table 3) shows the slump value for all concrete mixture produced, as well as the content of superplasticizer needed to obtain the consistency initially specified for the concrete, i.e., a slump value of (120 \pm 20$) \mathrm{mm}$. In most concrete mixtures, a slump loss was observed as the macrofiber content increased. In general, the addition of fibers decreases the workability of the concrete. Both surface area and high content of the fibers require a larger amount of cement paste to involve them, leading to an increase in the viscosity and a reduction in the slump of a concrete mix (Fallah and Nematzadeh, 2017). In addition, fibers constitute an obstacle to the movement of the aggregates, hindering the relative mobility between the particles and negatively affecting the workability of the material (Figueiredo and Ceccato, 2015). 
Table 3. Results of the slump test

\begin{tabular}{|c|c|c|}
\hline Concrete type & Admixture content (\%)* & Slump value (mm) \\
\hline CARR & 0.70 & 135 \\
\hline CAR1OPP & 1.00 & 120 \\
\hline CAR2OPP & 1.20 & 40 \\
\hline Note: * Admixture content relative to cement mass. \\
\hline
\end{tabular}

Both in CARR and in CAR1OPP it was possible to reach the desired slump range by adjusting the superplasticizer admixture content, which increased with the increase in the macrofiber content added to the concrete. However, in CAR2OPP it was not possible to obtain the desired slump value even with the addition of high content of admixture (Figure 1a). In this mixture the phenomena of exudation and segregation were observed with an increase in the admixture content (Figure 1b), indicating the impossibility of adding a larger amount of admixture, since the paste was fluid, but the large number of fibers prevented the concrete flow. To avoid total loss of the material, the addition of superplasticizer was limited by observing such phenomena. In the molding of the plates with CAR2OPP it was necessary to perform a more intensive and longer compaction on the vibrating table, due to the consistency of the mixture (Figure 1c). As found in this study and different from what (Mendonza et al., 2011) stated, it is not always possible to improve the workability of the fiber reinforced concrete by adding only superplasticizer admixture. In some cases, it may be necessary to change the concrete mix design, increasing the mortar content to achieve the desired workability, which allows to obtain a greater distance between the fibers and a better relative movement between the particles, as verified by (Figueiredo and Ceccato 2015). Moreover, in the production of CAR2OPP it was observed the formation of fiber agglomerates (clusters) (Figure 1d), impairing the homogeneity of the mixture.
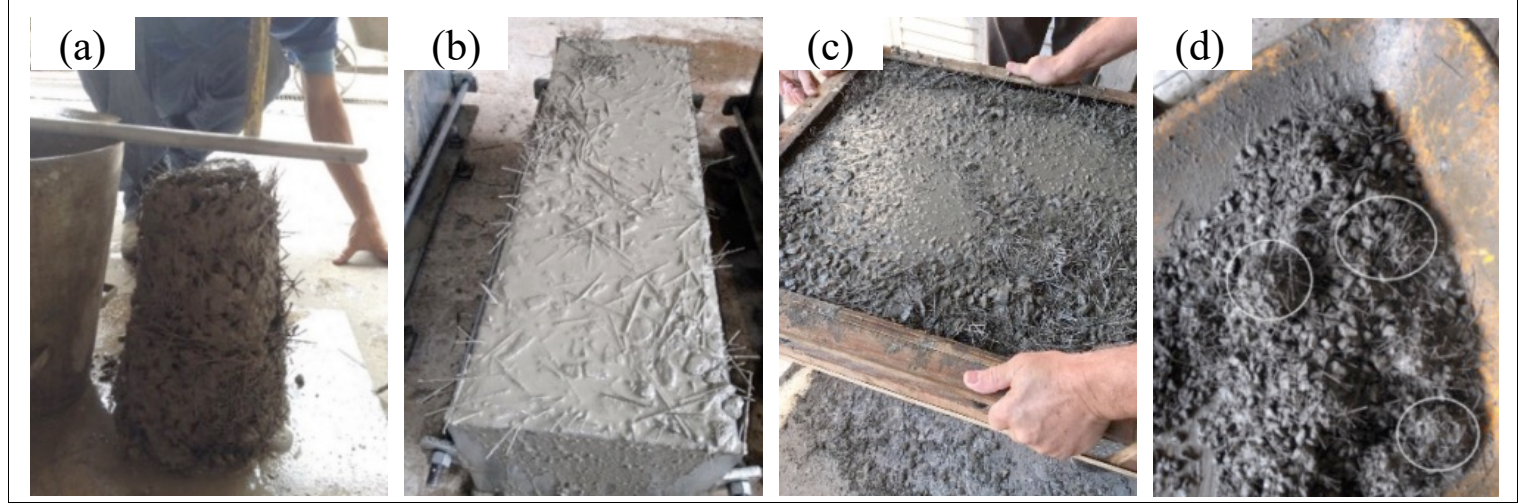

Figure 1. CAR2OPP: (a) slump test; (b) beginning of exudation and segregation in concrete; (c) compacting of the plates during the molding; (d) formation of macro-polymeric fiber agglomerates (clusters) during the concrete production

\subsection{Compressive strength}

(Table 4) presents the mean value of the compressive strength for the concrete mixtures, at 28 days of age $\left(f_{c m, 28}\right)$. The results correspond to the average of five individual values obtained in the test of the three concrete mixtures produced 
Table 4. Results of the compressive strength test

\begin{tabular}{|c|c|c|}
\hline \multirow{2}{*}{ Concrete type } & \multicolumn{2}{|c|}{$\boldsymbol{f}_{\text {cm2s }}$} \\
\cline { 2 - 3 } & Mean value (MPa) & CV (\%) \\
\hline CARR & 70.24 & 3.64 \\
\hline CAR1OPP & 73.52 & 1.60 \\
\hline CAR2OPP & 65.16 & 3.72 \\
\hline Note: $C V=$ coefficient of variation. \\
\hline
\end{tabular}

Due to their macro-scale and greater length, the macro-polymeric fibers do not effectively contribute to the load-carrying in concrete until the peak loading (maximum load) is reached. Beyond this load and near the sample failure is when these fibers begin to act as reinforcement elements, increasing ductility and preventing the propagation of cracks in the material (Fallah and Nematzadeh, 2017). Thus, comparing the compressive strength results of macro-polymeric fiber reinforced concrete (CAR1OPP and CAR2OPP) with those of non-fiber reference concrete (CARR), it was found that the addition of $1.0 \%$ by volume of macrofiber resulted in a slight increase in the strength $(4.7 \%)$, but at the content of $2.0 \%$ by volume, there was a reduction of $7.2 \%$ in the strength value. The statistical analysis (Table 5) indicates that the fiber content had a significant influence on the compressive strength value when higher fiber contents are used. It stands out that in samples of ordinary concrete containing macropolymeric fiber analyzed by (Leite, 2018), a significant difference was also observed in the compressive strength, even with the incorporation of low fiber contents.

Table 5. Student's t-test to evaluate the influence of fiber content on compressive strength

\begin{tabular}{|c|c|c|c|c|c|}
\hline $\begin{array}{c}\text { Compared } \\
\text { fiber content }\end{array}$ & $\boldsymbol{D F}$ & $\boldsymbol{t}$ & $\begin{array}{c}\boldsymbol{P}(\boldsymbol{T} \leq \boldsymbol{t}) \text { two- } \\
\text { tailed }\end{array}$ & Critical t & $\begin{array}{c}\text { Significant } \\
\text { difference? }\end{array}$ \\
\hline $0,0-1,0 \%$ & 7 & $-2,3516$ & 0,0510 & 2,3646 & No \\
\hline $1,0 \%-2,0 \%$ & 7 & 6,2735 & 0,0004 & 2,3646 & $Y e s$ \\
\hline $0,0-2,0 \%$ & 8 & 3,2267 & 0,0121 & 2,3060 & Yes \\
\hline
\end{tabular}

(Mehta and Monteiro, 2014) stated that the addition of low and moderate fiber contents should have little influence on the compressive strength of the concrete, with its main contribution occurring in the toughness of the composite, what was actually observed in the present study when comparing the mechanical performance of CARR and CAR10PP. However, the inadequate workability of the concrete with high content of macrofiber (CAR2OPP) may have influenced the loss of compressive strength, as it was observed the occurrence of fiber agglomerates (clusters) that lead to pore formation in the fiber reinforced concrete.

The moment of the failure in the compressive strength test of CARR and CAR1OPP is shown in Figures 2a and $2 b$, respectively. While the reference concrete crumbled into several parts, the specimen of the macro-polymeric fiber reinforced concrete remained practically intact after failure. Similar behavior was observed by (Andrade, 2013), when analyzing the properties of a self-compacting concrete reinforced with steel and polypropylene fibers. 


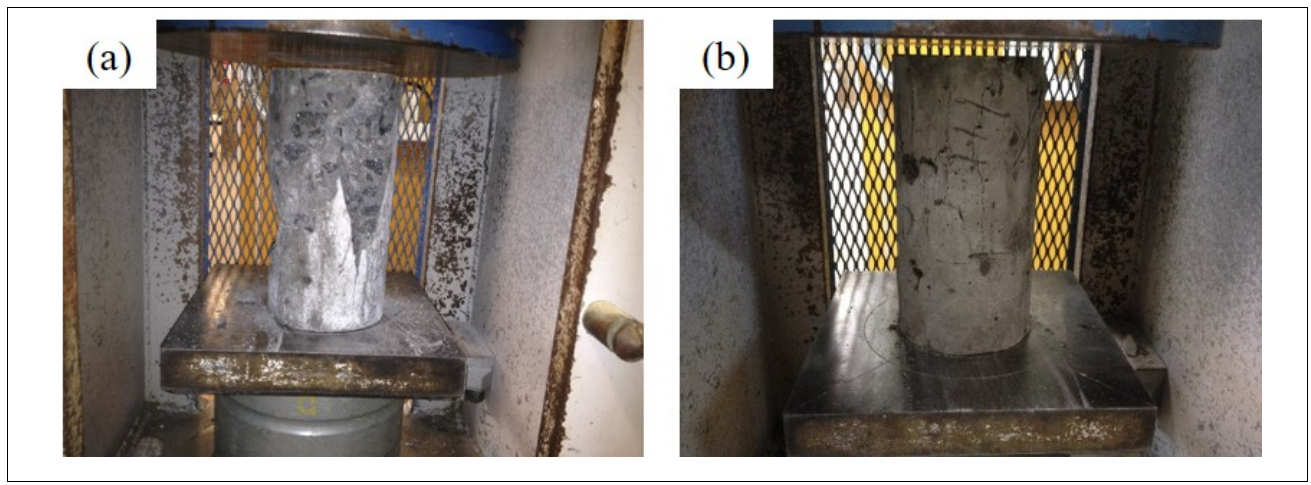

Figure 2. Compressive strength test: (a) CARR and (b) CAR10PP

\subsection{Barcelona test}

The Barcelona test was developed to overcome some challenges found in the execution of the traditional flexural test in prisms, such as the high variability of the results and the use of heavy samples that are difficult to transport and test setup (Malatesta et al., 2009). In this test, cylindrical specimens of height approximately equal to the diameter are used, metallic discs are placed on the bottom and top surfaces of the specimen for load application (double punching), and the increase in the total circumferential opening displacement (TCOD) of the specimen is measured, being the test ended when a TCOD of $6 \mathrm{~mm}$ is registered. From this test, it is obtained the tensile strength, toughness and residual tensile strength of a fiber reinforced concrete.

The specimens of CARR, CAR1OPP and CAR2OPP after the Barcelona test are shown in Figure 3. In CARR there was a catastrophic failure, with the specimen being divided into three parts (Figure 3a). In CAR10PP the formation of three or four cracks was predominant (Figure 3b), while in CAR2OPP there was the formation of up to five cracks (Figure 3c), due to the higher macrofiber content.
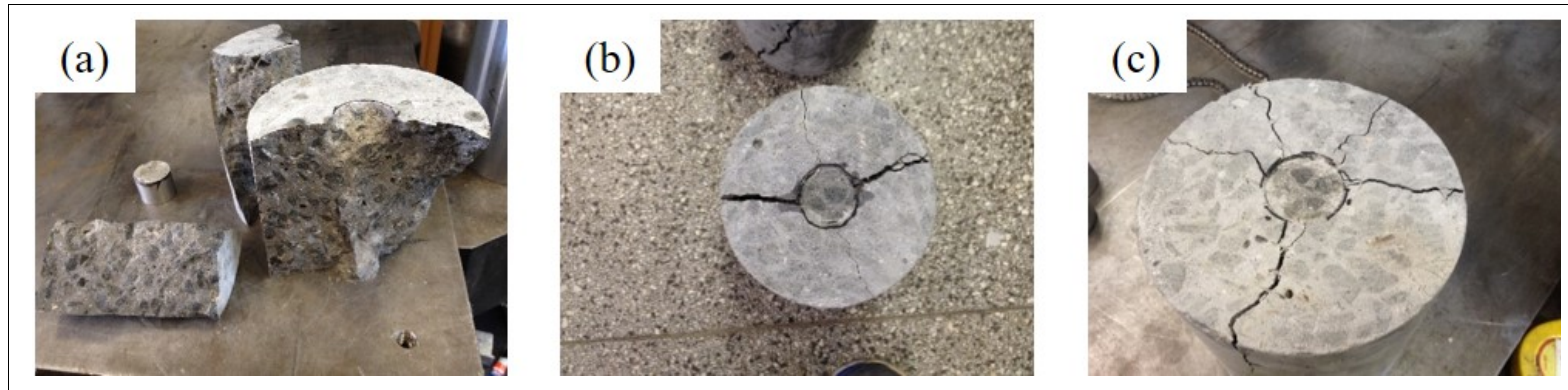

Figure 3. Barcelona test: (a) CARR, (b) CAR10PP and (c) CAR2OPP

As CARR presented a catastrophic failure when the concrete strength was reached, (Figure 4) shows only the load versus TCOD curves resulting from the test of high strength concrete samples with macro-polymeric fiber. In both macrofiber reinforced concrete, a post-peak instability and a softening behavior were verified, with reduction of the post-cracking resistant load. The post-peak instability phenomenon was observed during load application up to a TCOD of $1.0 \mathrm{~mm}$ and $0.5 \mathrm{~mm}$ in CAR10PP (Figure 4a) and CAR20PP (Figure 4b), respectively. The greatest instability occurred with the use of lower macrofiber contents (CAR1OPP). A similar behavior was observed in ordinary macro-polymeric fiber reinforced concrete analyzed by (Leite, 2018), that showed both post-peak instability and softening behavior. 
(a)

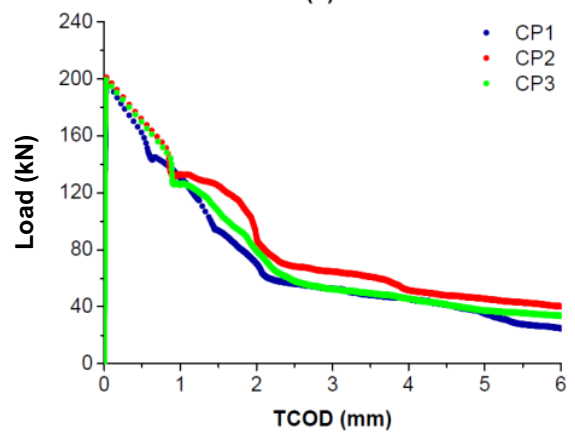

(b)

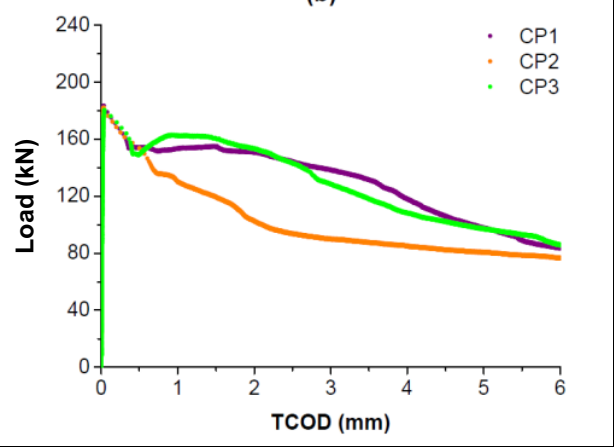

Figure 4. Barcelona test results - Load versus TCOD curves for high strength concrete with macropolymeric fiber in the content of (a) $1.0 \%$ and (b) $2.0 \%$, by volume

(Table 6) shows the Barcelona test results, emphasizing that the values presented refer to the average of three individual results obtained in the test of the mixtures produced. These results include tensile strength $\left(f_{c t}\right)$, toughness up to a TCOD of $6 \mathrm{~mm}$, residual strength for the TCOD of $1.5 \mathrm{~mm}\left(f_{C t, T C O D}=1.5\right)$ and of $6 \mathrm{~mm}\left(f_{C t, T C O D=6}\right)$, that correspond to the Service Limit State (SLS) and the Ultimate Limit State (ULS), respectively, as observed by (Monte et al., 2014).

Table 6. Results of the Barcelona test

\begin{tabular}{|c|c|c|c|c|c|c|c|c|}
\hline \multirow{2}{*}{$\begin{array}{c}\text { Concrete } \\
\text { type }\end{array}$} & \multicolumn{2}{|c|}{$f_{c t}(M P a)$} & \multicolumn{2}{|c|}{ Toughness (J) } & \multicolumn{2}{|c|}{$f_{C t, T C O D=1,5}(\mathrm{MPa})$} & \multicolumn{2}{|c|}{$f_{c t, T C O D=6}(M P a)$} \\
\hline & Mean & $C V$ & Mean & $C V$ & Mean & $C V$ & Mean & $C V$ \\
\hline$C A R R$ & 4.29 & 4.70 & - & - & - & - & - & - \\
\hline CAR10PP & 5.03 & 0.47 & 467.9 & 8.5 & 2.73 & 14.59 & 0.83 & 23.61 \\
\hline CAR2OPP & 4.58 & 0.89 & 722.5 & 13.3 & 3.64 & 15.43 & 2.06 & 5.78 \\
\hline
\end{tabular}

The tensile strength of the CAR10PP was the most affected by the macrofiber addition, with an increase of $17 \%$ in tensile strength when compared to CARR. The addition of $2.0 \%$, by volume, of macro-polymeric fiber resulted in a toughness increase of $54.4 \%$ in relation to the high strength concrete with $1.0 \%$, by volume, of macrofiber. According to Student's t-test (Table 7) and (Table 8), the macro-polymeric fiber content significantly influenced tensile strength and toughness of high strength concrete, as occurred in the ordinary concrete containing macro-polymeric fiber analyzed by (Leite, 2018).

Table 7. Student's t-test to evaluate the influence of fiber content on tensile strength by Barcelona test

\begin{tabular}{|c|c|c|c|c|c|}
\hline $\begin{array}{c}\text { Compared } \\
\text { fiber content }\end{array}$ & $\boldsymbol{D F}$ & $\boldsymbol{t}$ & $\begin{array}{c}\boldsymbol{P}(\boldsymbol{T} \leq \boldsymbol{t}) \text { two- } \\
\text { tailed }\end{array}$ & Critical t & $\begin{array}{c}\text { Significant } \\
\text { difference? }\end{array}$ \\
\hline $0,0-1,0 \%$ & 4 & $-6,3169$ & 0,0032 & 2,7764 & Yes \\
\hline $1,0 \%-2,0 \%$ & 4 & 16,5085 & 0,0001 & 2,7764 & Yes \\
\hline $0,0-2,0 \%$ & 4 & $-2,4398$ & 0,0712 & 2,7764 & No \\
\hline
\end{tabular}


For the residual strength, there was a percentage increase of $33.3 \%$ in $f_{C t, T C O D}=1.5$ and of $148 \%$ in $f_{C t, T C O D=6}$ with the increase of the macro-polymeric fiber content. According to Student's t-test (Table 8), the macro-polymeric

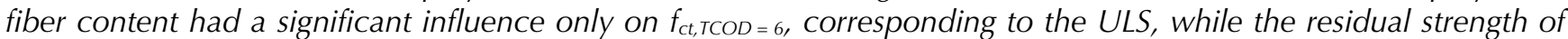
the high strength concrete in the SLS was not significantly affected. In ordinary concrete containing macropolymeric fiber analyzed by (Leite, 2018), a significant change was obtained for both residual strength in SLS and ULS.

Table 8. Student's t-test to evaluate the influence of fiber content on toughness, $f_{c t, T C O D}=1.5$ and $f_{c t, T C O D}=6$ by Barcelona test: comparison between samples with $1.0 \%$ and $2.0 \%$, by volume, of fiber content

\begin{tabular}{|c|c|c|c|c|c|}
\hline Property & $\boldsymbol{D F}$ & $\boldsymbol{t}$ & $\begin{array}{c}\boldsymbol{P}(\boldsymbol{T} \leq \boldsymbol{t}) \boldsymbol{t w o}- \\
\text { tailed }\end{array}$ & Critical t & $\begin{array}{c}\text { Significant } \\
\text { difference? }\end{array}$ \\
\hline Toughness & 4 & $-4,2510$ & 0,0131 & 2,7764 & Yes \\
\hline$f_{C t, T C O D=1.5}$ & 4 & $-2,2912$ & 0,0838 & 2,7764 & No \\
\hline$f_{C t, T C O D=6}$ & 4 & $-9,2442$ & 0,0008 & 2,7764 & Yes \\
\hline
\end{tabular}

\subsection{Flexural test in prisms}

Examples of the CARR, CAR1OPP and CAR2OPP specimens tested in the flexural test in prisms are shown in Figure 5. In CARR there was a catastrophic failure, with the split of the prismatic specimen into two parts (Figure 5a), while in CAR1OPP and CAR2OPP (Figures $5 b$ and 5c, respectively) predominated the formation of a crack in the central region of the specimen, between the load application points, without the complete separation of the prisms at the end of the test. In general, high strength concrete samples, without fiber addition, present a severe cracking condition when tested, suggesting the occurrence of a brittle fracture, while the presence of fibers in the concrete leads to a ductile fracture, being observed small cracks (Fallah and Nematzadeh, 2017.)
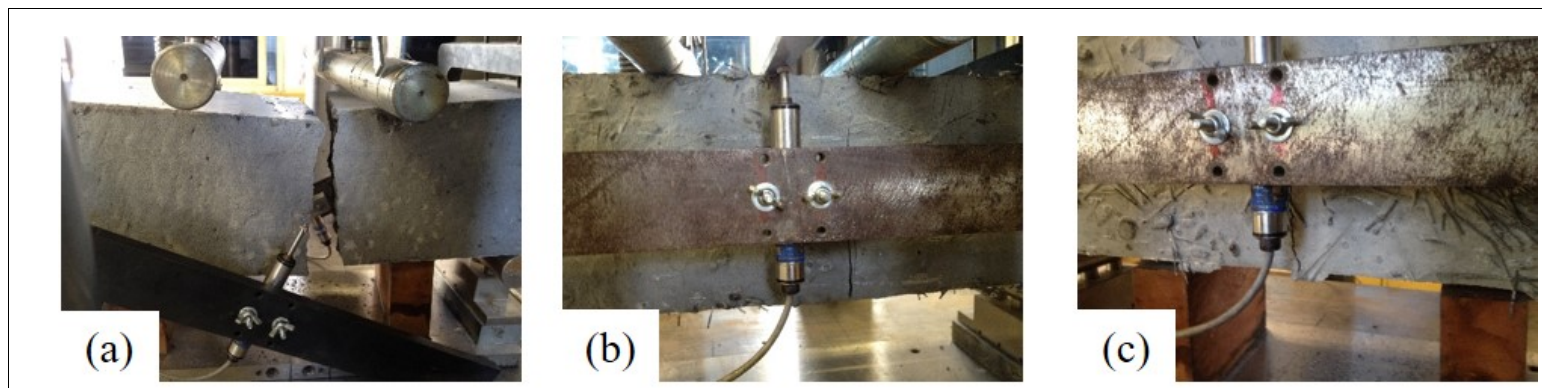

Figure 5. Flexural test in prisms: (a) CARR, (b) CAR1OPP and (c) CAR2OPP

As CARR presented a catastrophic failure when the flexural tensile strength was reached, Figure 6 shows only the load versus vertical displacement curves obtained by flexural test in prisms of high strength macro-polymeric fiber reinforced concrete. The highest post-peak instability was observed in the CAR1OPP samples (Figure 6a), which extended to a vertical displacement of $1.0 \mathrm{~mm}$ in one of the prisms. In CAR2OPP (Figures 6b), the instability ended at the displacement of $0.5 \mathrm{~mm}$. It is interesting to note that after the instability ceases, there was an increase of the resistant load with the increment of the displacement (slip-hardening behavior) in the two mixtures containing macro-polymeric fiber. This behavior is similar to that observed by (Lee et al., 2016) and (Amin et al,. 2017). 
(a)

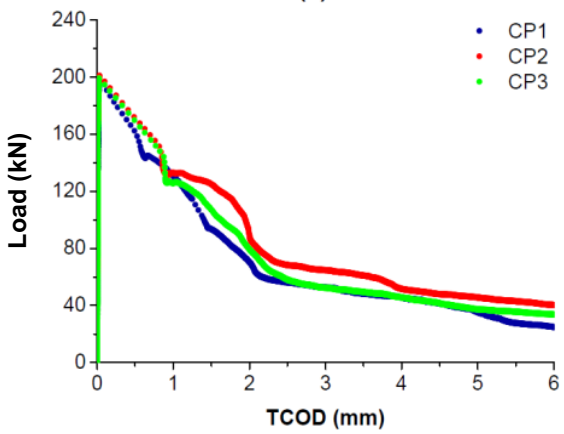

(b)

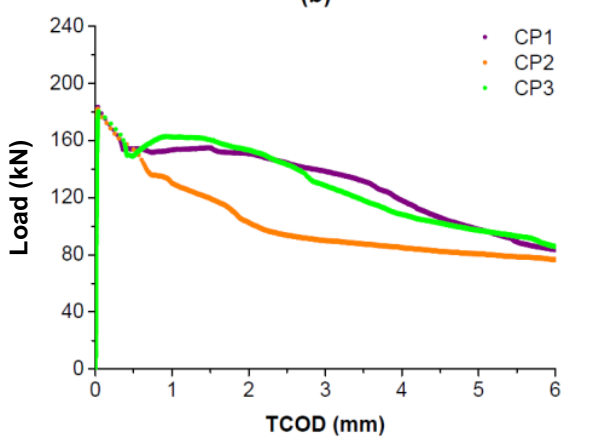

Figure 6. Flexural test results - Load versus vertical displacement curves for high strength concrete with macro-polymeric fiber in the content of (a) $1.0 \%$ and (b) $2.0 \%$, by volume

(Table 9) shows the results of the flexural test in prisms, whose mean values refer to the average of three individual results obtained in the test of the mixtures, including flexural tensile strength $\left(f_{c t, f}\right)$, toughness factor $\left(\overline{\boldsymbol{\sigma}}_{\boldsymbol{b}}\right)$, and residual strength in the displacements of $0.75 \mathrm{~mm}\left(\boldsymbol{\sigma}_{\boldsymbol{\sigma o o}}^{\boldsymbol{D}}\right)$ and $3.00 \mathrm{~mm}\left(\boldsymbol{\sigma}_{\mathbf{1 5 \boldsymbol { o }}}^{\boldsymbol{D}}\right)$.

Table 9. Results of the flexural test in prisms

\begin{tabular}{|c|c|c|c|c|c|c|c|c|}
\hline \multirow{2}{*}{$\begin{array}{c}\text { Concrete } \\
\text { type }\end{array}$} & \multicolumn{2}{|c|}{$\boldsymbol{f}_{\text {ct,f }}$ (MPa) } & \multicolumn{2}{c|}{$\overline{\boldsymbol{\sigma}}_{\boldsymbol{b}}$ (MPa) } & \multicolumn{2}{c|}{$\boldsymbol{\sigma}_{\boldsymbol{\sigma o o}}^{\boldsymbol{D}}(\mathbf{M P a})$} & \multicolumn{2}{c|}{$\boldsymbol{\sigma}_{\text {15o }}^{\boldsymbol{D}}$ (MPa) } \\
\cline { 2 - 10 } & Mean & $\boldsymbol{C V}$ & Mean & $\boldsymbol{C V}$ & Mean & $\boldsymbol{C V}$ & Mean & $\boldsymbol{C V}$ \\
\hline CARR & 7.97 & 2.49 & - & - & - & - & - & - \\
\hline CAR1OPP & 8.36 & 0.80 & 5.00 & 16.74 & 4.23 & 10.55 & 4.83 & 21.23 \\
\hline CAR2OPP & 7.82 & 2.83 & 5.89 & 10.05 & 4.91 & 9.82 & 6.46 & 17.31 \\
\hline
\end{tabular}

Note: $C V=$ coefficient of variation, in $\%$.

The presence of macro-polymeric fibers in cementitious matrices leads to reduced crack width and increased tensile strength. The crimped surface of the macro-polymeric fiber promotes a good adherence to the cement matrix along its length under tensile stresses. In addition, the high tensile strength and the long length of the macropolymeric fiber contribute to reducing the propagation of post-cracking macro-cracks, and thus significantly improves the tensile strength of the concrete (Fallah and Nematzadeh, 2017). In the present study, the addition of macro-polymeric fiber to high strength concrete practically unchanged the flexural tensile strength, regardless of the macrofiber content added. However, according to Student's t-test (Table 10), the addition of macro-polymeric fiber caused significant changes in flexural tensile strength.

Table 10. Student's t-test to evaluate the influence of fiber content on tensile strength by flexural test

\begin{tabular}{|c|c|c|c|c|c|}
\hline $\begin{array}{c}\text { Compared } \\
\text { fiber content }\end{array}$ & $\boldsymbol{D F}$ & $\boldsymbol{t}$ & $\begin{array}{c}\boldsymbol{P}(\boldsymbol{T} \leq \boldsymbol{t}) \text { two- } \\
\text { tailed }\end{array}$ & Critical $\boldsymbol{t}$ & $\begin{array}{c}\text { Significant } \\
\text { difference? }\end{array}$ \\
\hline $0,0-1,0 \%$ & 3 & $-3,4411$ & 0,0412 & 3,1824 & Yes \\
\hline $1,0 \%-2,0 \%$ & 4 & 4,0733 & 0,0152 & 2,7764 & Yes \\
\hline $0,0-2,0 \%$ & 3 & 0,7396 & 0,5131 & 3,1824 & No \\
\hline
\end{tabular}


The addition of double content of macro-polymeric fiber to the high strength concrete $(2.0 \%$, by volume) resulted in a toughness factor increase of $17.8 \%$ in relation to the result obtained with the macrofiber content of $1.0 \%$, by volume. With the increase of the macro-polymeric fiber content from $1.0 \%$ to $2.0 \%$, both by volume, in the high strength concrete, increases of $16.1 \%$ and $33.7 \%$ were obtained in the residual strength in SLS and ULS, respectively. However, according to the statistical analysis (Table 11), the improvement observed in the toughness factor and in the residual strength value, both in SLS and ULS, with the increase of the macro-polymeric fiber content was not significant. This behavior is similar to that observed by (Leite, 2018) in ordinary macro-polymeric fiber reinforced concrete

Table 11. Student's t-test to evaluate the influence of fiber content on toughness factor, residual strength in SLS and in ULS by the flexural test in prisms: comparison between samples with $1.0 \%$ and $2.0 \%$, by volume, of fiber content

\begin{tabular}{|c|c|c|c|c|c|}
\hline Property & DF & $\boldsymbol{t}$ & $\begin{array}{c}\boldsymbol{P}(\boldsymbol{T} \leq \boldsymbol{t}) \\
\text { two-tailed }\end{array}$ & Critical $\boldsymbol{t}$ & $\begin{array}{c}\text { Significant } \\
\text { difference? }\end{array}$ \\
\hline Toughness factor & 4 & $-1,4990$ & 0,2082 & 2,7764 & No \\
\hline Residual strength in SLS & 4 & $-1,7816$ & 0,1494 & 2,7764 & No \\
\hline Residual strength in ULS & 4 & $-1,8570$ & 0,1369 & 2,7764 & No \\
\hline
\end{tabular}

\subsection{Punching test in plates}

The failure of some plates produced with CARR, CAR1OPP and CAR2OPP in the punching test are shown in (Figure 7). In CARR, once again, there was a catastrophic failure, with the split of the plate into four parts, highlighting the brittle fracture of the element (Figure 7a). On the other hand, in CAR1OPP (Figure 7b) and CAR20PP (Figure 7C) predominated the formation of four or five cracks, with the failure of some fibers and the pullout of others, indicating a ductile fracture of the plates. By a round panel test, quite similar to the punching test in plates performed in the present study, Amin et al. (2017) expected that the cracks in the round panel specimens should form midway between the supports where the applied moment is the greatest; however, the development of most cracks occurred in some degrees of the theoretical failure plane, and the authors attributed this deviation to the variation of concrete matrix strength within the specimen and the sensitivity of the fracture processes to this variation.

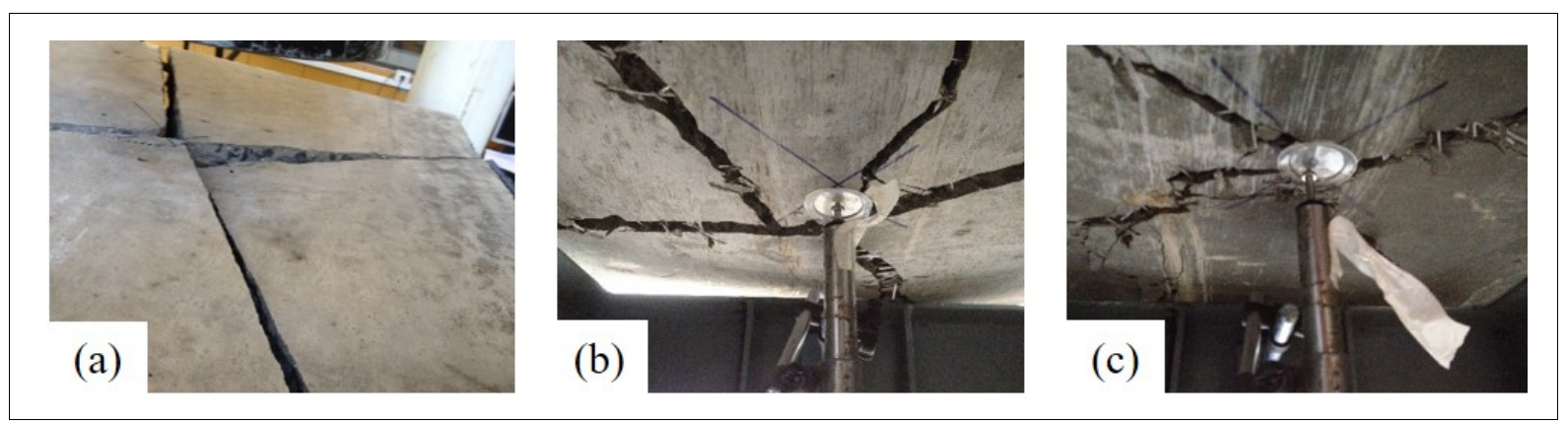

Figure 7. Punching test in plates: (a) CARR, (b) CAR10PP and (c) CAR2OPP

As CARR presented a catastrophic failure when the load capacity of the plate was reached, (Figure 8) shows only the load versus center displacement curves resulting from the punching test in plates of high strength concrete with macro-polymeric fiber. Both high strength macro-polymeric fiber reinforced concrete presented oscillations in resistant load value after the cementitious matrix failure, predominating the slip-hardening behavior. According to (Figueiredo, 2011), the formation of multiple cracks that occur in small displacements causes these oscillations, that stabilizes at a given time. In concrete mixtures produced and evaluated in the present study, the maximum load was reached with a center displacement of approximately $7.5 \mathrm{~mm}$. The post-peak instability phenomenon was observed in both CAR10PP and CAR2OPP. 

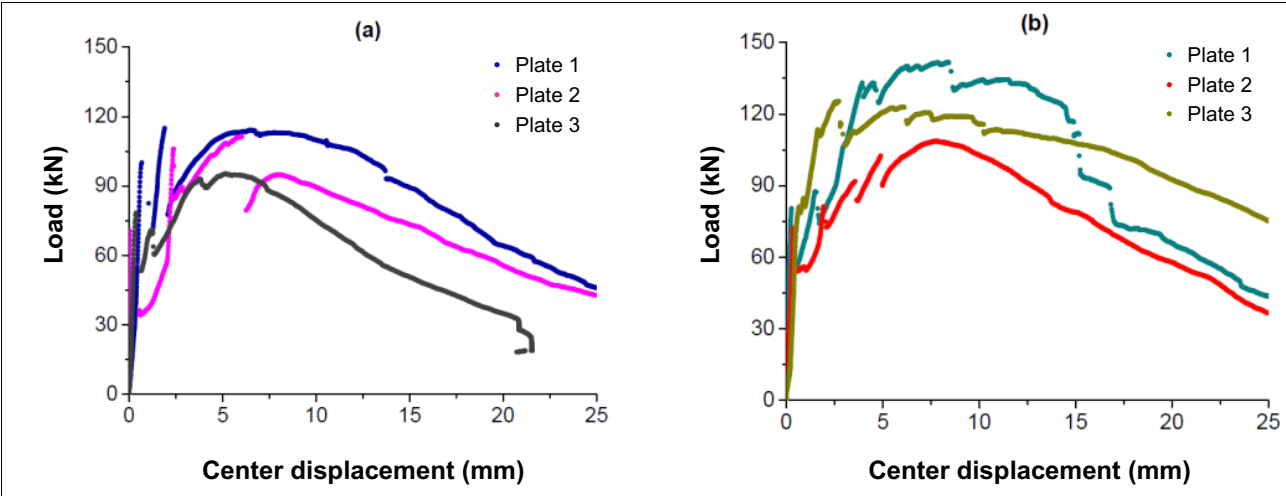

Figure 8. Punching test results - Load versus center displacement curves for high strength concrete with macro-polymeric fiber in the content of (a) $1.0 \%$ and (b) $2.0 \%$, by volume

In the round panel tests performed by (Amin et al., 2017), the formation of three dominant radial cracks in all specimens coincided with a reduction in the resistant capacity of the panels. However, the authors observed that the initial load after cracking had dropped well below that of the peak residual strength of the high strength fiber reinforced concrete, showing a progressively smooth residual capacity lost of the specimens. A similar behavior was observed in the high strength macro-polymeric fiber reinforced concrete mixtures evaluated in the present study by the punching test in plate, regardless of the macro-polymeric fiber content added.

(Table 12) presents the punching test results for each concrete mixture produced, including the maximum load and toughness up to a center displacement of $25 \mathrm{~mm}$. The mean value refers to the average of three individual results obtained from the test of high strength macro-polymeric fiber concrete mixtures produced.

Table 12. Results of the punching test in plates

\begin{tabular}{|c|c|c|c|c|}
\hline \multirow{2}{*}{ Concrete type } & \multicolumn{2}{|c|}{ Maximum load (kN) } & \multicolumn{2}{c|}{ Toughness (J) } \\
\cline { 2 - 5 } & Mean & $C \boldsymbol{V}$ & Mean & $\boldsymbol{C}$ \\
\hline CARR & 83.17 & 8.42 & - & - \\
\hline CAR10PP & 107.23 & 9.77 & 1795.41 & 21.98 \\
\hline CAR2OPP & 125.24 & 13.13 & 2332.12 & 15.19 \\
\hline Note: $C V=$ coefficient of variation, in \%. \\
\hline
\end{tabular}

From the punching test in plates, it was possible to verify the macro-polymeric fiber contribution to the mechanical performance of the high strength concrete mixtures under tensile stresses, as observed by (Amin et al., 2017), (Fallah and Nematzadeh, 2017). Increases of $28.8 \%$ and $50.6 \%$ were observed in the maximum load of the high strength concrete with the addition of macro-polymeric fiber in the contents of $1.0 \%$ and $2.0 \%$ (both in volume), respectively, in relation to the sample without macrofiber (CARR). According to the statistical analysis (Table 13), the macro-polymeric fiber content caused significant changes in the maximum resistant load of the plates, different of the behavior observed in ordinary macro-polymeric fiber reinforced concrete, whose difference was considered not significant (Leite, 2018). 
Table 13. Student's t-test to evaluate the influence of fiber content on maximum load by punching test

\begin{tabular}{|c|c|c|c|c|c|}
\hline $\begin{array}{c}\text { Compared } \\
\text { fiber } \\
\text { content }\end{array}$ & DF & $\boldsymbol{t}$ & $\begin{array}{c}\boldsymbol{P}(\boldsymbol{T} \leq \boldsymbol{t}) \\
\text { two-tailed }\end{array}$ & Critical $\boldsymbol{t}$ & $\begin{array}{c}\text { Significant } \\
\text { difference? }\end{array}$ \\
\hline $0,0-1,0 \%$ & 4 & $-3,3078$ & 0,0297 & 2,7764 & $Y e s$ \\
\hline $1,0 \%-2,0 \%$ & 4 & $-1,5998$ & 0,1849 & 2,7764 & No \\
\hline $0,0-2,0 \%$ & 4 & $-4,0766$ & 0,0151 & 2,7764 & Yes \\
\hline
\end{tabular}

In toughness, an increase of $29.9 \%$ was obtained when the content of macro-polymeric fiber rose from $1.0 \%$ to $2.0 \%$, both in volume. However, the statistical analysis (Table 14) considered that the variation in toughness is not significant when the content of macrofiber increases in the composition of the high strength concrete, being similar to the behavior observed in ordinary macro-polymeric fiber reinforced concrete evaluated by (Leite, 2018).

Table 14. Student's t-test to evaluate the influence of fiber content on toughness by punching test: comparison between samples with $1.0 \%$ and $2.0 \%$, by volume, of fiber content

\begin{tabular}{|c|c|c|c|c|c|}
\hline Property & DF & $\boldsymbol{t}$ & $\begin{array}{c}\boldsymbol{P}(\boldsymbol{T} \leq \boldsymbol{t}) \\
\text { two- } \\
\text { tailed }\end{array}$ & Critical $\boldsymbol{t}$ & $\begin{array}{c}\text { Significant } \\
\text { difference? }\end{array}$ \\
\hline Toughness & 4 & $-1,7529$ & 0,1545 & 2,7764 & No \\
\hline
\end{tabular}

\subsection{Synthesis of statistical analysis}

The synthesis of the statistical analysis of the influence of the macro-polymeric fiber addition on the properties of the high strength concrete is presented in Table 15. The increase in the macro-polymeric fiber content caused significant changes in approximately half of the properties analyzed: compressive strength; tensile strength, toughness and residual strength in ULS, measured by Barcelona test; tensile strength measured by the flexural test in prisms; and maximum load measured by the punching test in plates. On the other hand, the increase in the macrofiber content did not caused significant changes in the residual strength in SLS measured by the Barcelona test, toughness factor, residual strength in SLS and in ULS measured by the flexural test in prisms, and the toughness measured by the punching test in plates. 
Table 15. Synthesis of statistical analysis of the influence of macro-polymeric fiber addition on the properties of the high strength concrete

\begin{tabular}{|c|c|c|c|c|c|c|c|c|c|c|}
\hline 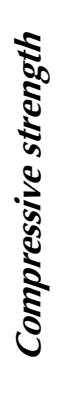 & 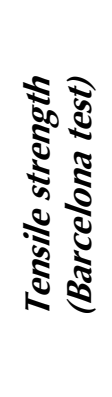 & 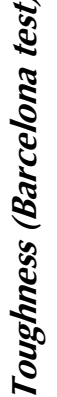 & 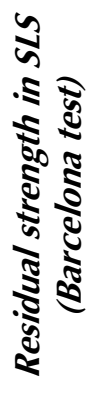 & 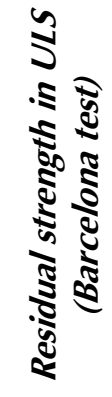 & 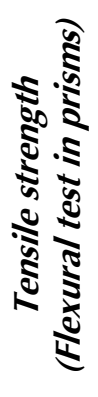 & 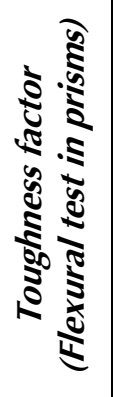 & 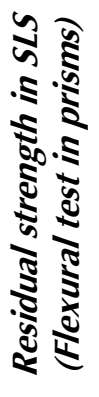 & 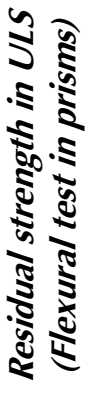 & 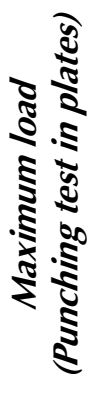 & 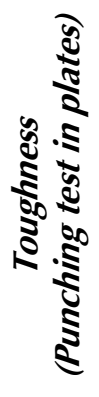 \\
\hline & & & & & & & & & & \\
\hline \multicolumn{3}{|c|}{ Legend: } & & \multicolumn{3}{|c|}{ Not significant difference } & & \multicolumn{3}{|c|}{ Significant difference } \\
\hline
\end{tabular}

Just as the same concrete mixture showed different behavior depending on the test method performed, the influence of the macro-polymeric fiber addition also varied depending on the property evaluated, which may or may not result in significant changes in the behavior of the high strength macro-polymeric fiber reinforced concrete. Thus, depending on the property of interest and the test method, it is possible to observe or not the contribution of the macro-polymeric fiber as a primary reinforcement element for high strength fiber reinforced concrete.

\section{Conclusion}

In general, the addition of macro-polymeric fiber reduced the workability of the concrete, requiring the increase of superplasticizer admixture to reach the initially set slump value. However, the desired slump could not be achieved for the mixture with high macrofiber content, even with the addition of superplasticizer. During the production of this mixture, it was observed the formation of fiber agglomerates (clusters), compromising its homogeneity.

Regarding the mechanical properties, it was found that the content of macro-polymeric fiber had a significant influence on the compressive strength, reducing this property with the increase of the macrofiber content, which may have been influenced by the inadequate workability of the concrete with high content of macrofiber. For the other mechanical properties evaluated, depending on the property of interest, the increase of the macro-polymeric fiber content may be unfeasible. In Barcelona test, macrofiber content had a significant influence on tensile strength, toughness and residual strength in the ULS. In the flexural test in prisms, with the exception of the flexural tensile strength, the other parameters evaluated (toughness, residual strength in SLS and ULS) did not show significant changes with the increase in the macrofiber content. In the punching test in plates, only the maximum load was significantly changed with the macro-polymeric fiber addition; however, neither the maximum load nor toughness changed significantly with the increase in the macrofiber content added.

The tests considered to determine the toughness of the high strength macro-polymeric fiber reinforced concrete - Barcelona, flexural in prisms and punching in plates - presented different cracking patterns. While in the prisms the formation of only one crack predominated, in the cylinders and plates there was the formation of multiple cracks. When comparing the three test methods, it is observed that the post-peak instability occurred more pronounced in the flexural test in prisms, being noticeable by the greater distance between the points of the load versus displacement curve.

Finally, it is important to emphasize that the same concrete mixture may present different behavior depending on the test performed. The high strength concrete mixtures containing macro-polymeric fiber showed softening behavior in the Barcelona test, while in the flexural test in prisms and punching test in plates presented slip-hardening behavior. 


\section{Acknowledgments}

The authors thank the Coordenação de Aperfeiçoamento de Pessoal de Nível Superior (CAPES) for funding the research scholarship, and the companies Votorantim Cimentos, GCP Applied Technologies and Tecnosil for donating the materials used in the study.

\section{References}

ABNT. Associação Brasileira de Normas Técnicas (1998). NBR NM 67: Concrete: slump test for determination of the consistency, Rio de Janeiro, RJ, Brazil. (in Portuguese).

ABNT. Associação Brasileira de Normas Técnicas (2006). NBR NM 45: Aggregates: determination of the unit weight and air-void contents, Rio de Janeiro, RJ, Brazil (in Portuguese).

ABNT. Associação Brasileira de Normas Técnicas (2018). NBR 5739: Concrete: compression test of cylindrical specimens, Rio de Janeiro, RJ, Brazil, (in Portuguese).

AENOR. Asociación Española de Normalización y Certificación. (2010). UNE 83515: Fibre reinforced concretes: determination of cracking strength, ductility and residual tensile strength - Barcelona test, Madrid, Spain. (in Spanish).

Amin, A.; Foster, S.; Gilbert, R.; Kaufmann, W. (2017). Material characterization of macro synthetic fibre reinforced concrete. Cement and Concrete Composites, v.84, p.124-133. DOI: 10.1016/j.cemconcomp.2017.08.018

Andrade, M. F. (2013). Comparison of the toughness between ordinary concrete, steel fiber reinforced concrete and polypropylene fiber reinforced concrete. Master thesis, Universidad Politécnica de Madrid, Madrid, Spain (in Spanish).

Buratti, N.; Mazzotti, C.; Savoia, M. (2011). Post-cracking behaviour of steel and macro-synthetic fibre-reinforced concretes. Construction and Building Materials, v.25, p.2713-2722. DOI: 10.1016/j.conbuildmat.2010.12.022

EFNARC. European Federation of Producers and Applicators of Specialist Products for Structures (1996). European specification for sprayed concrete, Farnham, UK.

Fallah, S.; Nematzadeh, M. (2017). Mechanical properties and durability of high-strength concrete containing macro-polymeric and polypropylene fibers with nano-silica and silica fume. Construction and Building Materials, v.132, p.170-187. DOI: 10.1016/j.conbuildmat.2016.11.100

Figueiredo, A. D. (2000). Steel fiber reinforced concrete. Technical Bulletin, Polytechnic School of University of São Paulo, São Paulo, SP, Brazil (in Portuguese).

Figueiredo, A. D. (2011). Fiber reinforced concrete. Habilitation thesis, Polytechnic School of University of São Paulo, São Paulo, SP, Brazil (in Portuguese).

Figueiredo, A. D.; Ceccato, M. R. (2015). Workability analysis of steel fiber reinforced concrete using slump and Ve-Be test. Materials Research., v.8, p.1284-1290. DOI: 10.1590/1516-1439.022915

JSCE. The Japan Society of Civil Engineers (1984). JSCE-SF4: Method of tests for flexural strength and flexural toughness of steel fiber reinforced concrete, Concrete library of JSCE, part III-2, Tokyo, Japan, p.58-61.

Lee, Jong-Han; Cho, Baiksoon; Choi, Eunsoo; Kim, Yong-Hyung (2016). Experimental study of the reinforcement effect of macro-type high strength polypropylene on the flexural capacity of concrete. Construction and Building Materials, v.126, p.967-975. DOI: 10.1016/j.conbuildmat.2016.09.017

Leite, A. M. (2018). Evaluation of the use of polymeric macrofiber in the concrete composition for structural purposes. Master thesis, São Carlos School of Engineering, University of São Paulo, São Carlos, SP, Brazil (in Portuguese).

Leite, A. M.; Castro, A. L. (2020). Influence of the cementitious matrix on the behavior of fiber reinforced concrete. IBRACON Structural and Materials Journal, v.13, p.543-562. DOI: 10.1590/S1983-41952020000300006

Malatesta, S. C. et al. (2009). Quality control of fiber reinforced concretes by mean of double punching test (Barcelona test). Revista de Ingeniería de Construcción, v.24 (2), p.119-140. DOI: 10.4067/S0718-50732009000200001

Medeiros, A. (2012). Study of the compressive fatigue behavior of fiber reinforced concrete. Ph.D. thesis, Pontifical Catholic University, Rio de Janeiro, RJ, Brazil (in Portuguese).

Mehta, P. K.; Monteiro, P. J. M. (2014). Concrete: microstructure, properties and materials, 2.ed., Ibracon, São Paulo, SP, Brazil (in Portuguese). ISBN: 978-85-98576-21-3

Mendoza, C. J.; Aire, C.; Dávila, P. (2011). Influence of polypropylene fibers on concrete properties in plastic and hardened states. Concreto y Cemento: investigación y desarrollo, v.2, p.35-47 (in Spanish).

Monte, R.; Toaldo, G. S.; Figueiredo, A. D. (2014). Toughness evaluation of fiber reinforced concrete using open-loop test. Matéria, v.19, p.132149 (in Portuguese). DOI: 10.1590/S1517-70762014000200008

Salvador, R. P.; Figueiredo, A. D. (2013). Comparative evaluation of the mechanical behavior of synthetic and steel fiber-reinforced concrete. Matéria, v.18, p.1273-1285 (in Portuguese). DOI: 10.1590/S1517-70762013000200003

The Concrete Society. (2007). Guidance on the use of macro-synthetic-fibre-reinforced concrete, Cromwell Press, Trowbridge, UK. ISBN: 1 904482-34-1. 